\title{
The Effect of Power-walking in Phase 2 Cardiac Rehabilitation Program
}

\author{
Chul Kim, M.D., Byung Ok Kim, M.D. ', Kil-Byung Lim, M.D. ${ }^{2}$, Young Joo Kim, Ph.D., Yong Bum Park, M.D. \\ Departments of Rehabilitation Medicine, ${ }^{1}$ Internal Medicine, Sanggye Paik Hospital, Inje University College of Medicine, Seoul \\ 139-707, ${ }^{2}$ Department of Rehabilitation Medicine, Ilsan Paik Hospital, Inje University College of Medicine, Goyang 411-706, Korea
}

Objective To evaluate the effects of power walking (PW) training on a treadmill in patients with coronary heart disease (CHD) and to compare the cardiovascular effects of PW with usual walking (UW).

Method Patients were recruited as participants in phase 2 cardiac rehabilitation program after receiving percutaneous coronary intervention (PCI) due to acute coronary syndrome from our hospital. The participants were divided into the PW group $(n=16)$ and UW group $(n=18)$. All participants received graded exercise test (GXT) and significant difference in maximal oxygen consumption $\left(\mathrm{VO}_{2 \mathrm{Max}}\right)$ was not observed between the groups. Aerobic exercise training on treadmill was given for 50 minutes per session, three times a week, for six weeks. Physiological and hematological parameters were tested before and 6 weeks after the cardiac rehabilitation program. Exercise duration, $\mathrm{VO}_{2 \mathrm{Max}}$, heart rate, blood pressure, and rate pressure product were evaluated through graded exercise test. Hematological measurements included serum lipid profile, and high-sensitivity C reactive protein (hs-CRP). Results There were no significant differences in resting heart rate, maximal heart rate, resting systolic and diastolic blood pressures, lipid profile, hs-CRP, $\mathrm{VO}_{2 \mathrm{Max}}$, and $\mathrm{RPP}$ between the PW group and UW group. However, after 6 weeks of the intervention, $\mathrm{VO}_{2 \mathrm{Max}}$ in the $\mathrm{PW}$ group $(36.03 \pm 5.69 \mathrm{ml} / \mathrm{kg} / \mathrm{min})$ was significantly higher than that in the UW group $(29.73 \pm 5.63 \mathrm{ml} / \mathrm{kg} / \mathrm{min})(\mathrm{p}<0.05)$.

Conclusion After six weeks of phase 2 cardiac rehabilitation program, the PW group showed significant improvement in $\mathrm{VO}_{2 \mathrm{Max}}$ than the UW group. Thus, it will beneficial to recommend power walking in cardiac rehabilitation program.

Key Words Cardiovascular disease, Exercise, Walking, Rehabilitation

Received December 6, 2010; Accepted October 18, 2011

Corresponding author: Yong Bum Park

Department of Rehabilitation Medicine, Sanggye Paik Hospital, Inje University College of Medicine, 761-1, Sanggye 6,7 dong, Nowon-gu, Seoul 139-707, Korea

Tel: +82-2-950-1390, Fax: +82-2-935-3076, E-mail: swc328@naver.com (c) This is an open-access article distributed under the terms of the Creative Commons Attribution Non-Commercial License (http:// creativecommons.org/licenses/by-nc/3.0) which permits unrestricted noncommercial use, distribution, and reproduction in any medium, provided the original work is properly cited.

Copyright () 2012 by Korean Academy of Rehabilitation Medicine

\section{INTRODUCTION}

Improvement in physical activity and exercise capacity is important in primary and secondary preventions of cardiovascular disease. ${ }^{1}$ The positive effects of walking on exercise capacity and physical health along with metabolic and psychological health ${ }^{2-4}$ for healthy people, as well as for people with various chronic disorders have been proven through research. ${ }^{5-9}$ Walking exercise and energy consumption has a U-shaped relationship, where decreased walking speed leads to increased need for 
energy or oxygen consumption. A normal adult walking at a speed of $4.50-4.86 \mathrm{~km} / \mathrm{hr}$ has the least aerobic requirement and relatively low exercise intensity. It has been reported that running is preferred over walking at a speed equal to or greater than $8 \mathrm{~km} / \mathrm{hr}$, since running at the higher speed consumes less oxygen than walking. ${ }^{10,11}$ Moreover, the degree of stride width during walking exercise could greatly affect the aerobic demands during walking exercise, since increased speed increases the stride width and vice versa. Walking exercise at a speed around $4.67-4.81 \mathrm{~km} / \mathrm{hr}$ could especially be effective in improving cardiovascular endurance, as well as weight and percent body fat reduction in middle-aged adults with sedentary lifestyles. ${ }^{12}$

Power walking is a form of exercise where active upper body movement is added to the usual walking exercise. Power walking is a fast walking exercise done at a speed of 6 to $8 \mathrm{~km} / \mathrm{h}$ with the back straight and the center of gravity moving from heal, sole, and to hallux. The elbow joints are bent 90 degrees to actively swing back and forth during movement. ${ }^{12}$

The energy consumption increases up to $55 \%$ in walking exercise with the arm movement in comparison to just walking exercise without arm movement. Power walking has advantages of greater energy consumption than with running at a speed equal to or greater than $8 \mathrm{~km} /$ hr. Moreover, power walking consumes comparatively greater energy during exercise, while being at a lower intensity. Despite the advantages of power walking, the exercise effects have not been reported in cardiac rehabilitation programs. ${ }^{13}$

Therefore, the effects of power walking on cardiac rehabilitation have been evaluated in this study by dividing the cardiac rehabilitation patients into the power walking group and regular walking group for their exercise capacities.

\section{MATERIALS AND METHODS}

\section{Subjects}

The subjects were patients who had been diagnosed with acute coronary syndrome and had undergone percutaneous coronary intervention (PCI). The patients were enrolled at our rehabilitation clinic for graded exercise test and 6 weeks of aerobic exercise program under clinical surveillance; this was a phase 2 of a cardiac rehabilitation program. The patients enrolled as participants to the study after detailed explanations of the purpose and procedures of the study. Those patients with contraindications to exercise or clinical risk factors, such as musculoskeletal, neurological, pulmonary or metabolic disorder were all excluded from the study.

\section{Graded exercise test (GXT)}

Symptom-limited exercise tolerance tests were carried out using a modified Bruce protocol, which is a GXT protocol for cardiovascular disorder patients with a gradual increase in the exercise loads. The test was terminated according to the American Heart Association's (AHA) early termination criteria upon monitoring of abnormal chest pain, blood pressure, pulse, EKG, or subjective symptoms by the patients such as dizziness or light headedness. ${ }^{14} \mathrm{~A}$ real-time recording 12-channel EKG for GXT Q4500 (Quinton Instrument Co., Boston, USA), a respiratory gas analyzer Quinton metabolic cart (Quinton Instrument Co., Boston, USA), an automatic blood pressure and pulse monitor Model412, (Quinton Instrument Co., Boston, USA), and a treadmill for GXT Medtrack ST 55 (Quinton Instrument Co., Boston, USA) were used during the test. Resting heart rate, maximal heart rate, resting systolic and diastolic blood pressure, resting diastolic blood pressure, maximum exercise duration, metabolic equivalents (METs), resting and maximal heart rates, blood pressure, maximal and submaximal rate pressure product (RPP), and $\mathrm{VO}_{2 \max }$ were recorded during graded exercise test for all patients. Borg's rate of perceived exertion with 6-20 scale was used to measure the rate of perceived exertion (RPE). Administration of all medications was requested to either discontinue or maintain existing dosage for the duration of graded exercise test and exercise program. All patients received treatment at the department of internal medicine as inpatients, followed by a visit to the cardiac rehabilitation clinic for exercise tolerance tests within a week of discharge. The patients participated in the cardiac rehabilitation program one to 2 days after graded exercise tests with the exercise intensity calculated based on the Karvonen formula ${ }^{15}$ (maximal heart rate resting heart rate $\mathrm{x}$ exercise intensity $(\%)+$ resting heart rate) with the target heart rate (\%) between $60 \%$ and $85 \%$ for exercise intensity. Heart rates and ECG (myocardial ischemia and arrhythmia) were monitored real-time with 

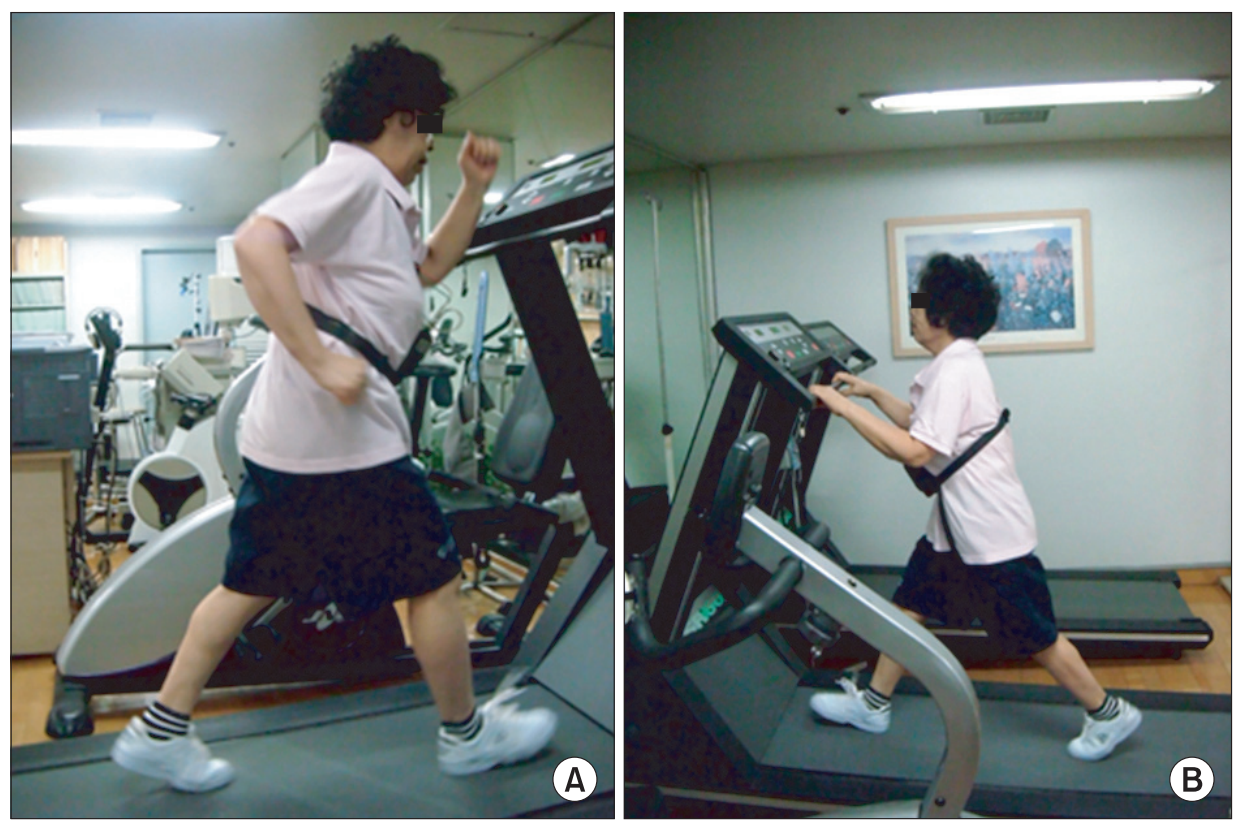

Fig. 1. The power walking group (A) was instructed to swing both arms back and forth while the elbow joint was bent at 90 degrees. The usual walking group (B) was instructed to intermittently grasp on the handles for safety during walking.

a wireless EKG attached to the patients during the cardiac rehabilitation exercise program. Blood pressure was measured 2 minutes prior to the termination of exercise. The exercise intensity was limited to the target heart rate of 60 to $85 \%$ based on the Karvonen formula.

\section{Exercise procedure and measured parameters}

Cardiac rehabilitation exercise was conducted 3 times a week for 6 weeks with the elbow joints flexed to 90 degrees and the arms swung back and forth during walking. The exercise intensities were set at $60 \%$ of the target heart rate during the first 2 weeks, $70 \%$ during $3^{\text {rd }}$ and $4^{\text {th }}$ weeks, and $85 \%$ during $5^{\text {th }}$ and $6^{\text {th }}$ weeks. Identical exercise protocol was prescribed to the UW group except for intermittently holding onto the handles while walking (Fig. 1). Resting heart rate (RHR), maximal heart rate (MHR), resting systolic blood pressure (RSBP), resting diastolic blood pressure (RDBP), maximal oxygen consumption $\left(\mathrm{VO}_{2 \max }\right)$, maximal exercise duration, and metabolic equivalent (MET) were measured via graded exercise test (GXT) and lipid profile and hs-CRP were tested through hematological analysis after 6 weeks of cardiac rehabilitation program for comparison.

\section{Statistical analysis}

The results were analyzed for means and standard deviations with SPSS/PC+ version 12.0, a statistical package for Windows. Chi-square test and Wilcox's rank-sum test were conducted to compare age, sex, BMI, diagnosis, lipid profile, and medication between the groups. Wilcoxon's rank-sum test and conducted to compare the test variables before and after exercise between the groups. Wilcoxon's signed rank test was conducted to compare the mean differences of the variables between the groups and pre and post exercise. The significance level was set at $\mathrm{p}<0.05$.

\section{RESULTS}

\section{General characteristics of the subjects}

The subjects were randomly assigned into either the power walking group (PW) or usual walking group (UW) for the study. The mean ages were 55.25 \pm 10.28 and $59.00 \pm 9.4$ for $\mathrm{PW}(\mathrm{n}=16)$ and $\mathrm{UW}(\mathrm{n}=18)$, respectively. PW was composed of 14 men and 2 women, and UW was composed of 17 men and 1 woman. There were no significant differences in body mass index (BMI), medication, past history, physical status, exercise capacity, pre-exercise lipid profile or hs-CRP, between the groups (Table 1).

\section{Changes in exercise capacity}

Resting heart rate (RHR), maximal heart rate (MHR), resting systolic blood pressure (RSBP), resting diastolic blood pressure (RDBP), rate pressure product (RPP), metabolic equivalent (MET), exercise duration, and 
Table 1. General Characteristics of the Subjects

\begin{tabular}{|c|c|c|c|}
\hline & PW $(n=16)$ & UW (n=18) & p-value \\
\hline Age (years) & $55.25 \pm 10.28$ & $59.00 \pm 9.47$ & 0.279 \\
\hline Sex (male) & $14(87.5 \%)$ & $17(94.4 \%)$ & 0.591 \\
\hline BMI & $25.46 \pm 2.64$ & $24.62 \pm 1.68$ & 0.289 \\
\hline \multicolumn{4}{|l|}{ Past history } \\
\hline Unstable angina & $8(50.0 \%)$ & $6(33.3 \%)$ & \\
\hline Myocardial infarction & $8(50.0 \%)$ & $12(66.7 \%)$ & 0.324 \\
\hline \multicolumn{4}{|l|}{ Lipid profile } \\
\hline Total cholesterol (mg/dl) & $179.94 \pm 45.50$ & $194.56 \pm 43.74$ & 0.347 \\
\hline $\mathrm{TG}(\mathrm{mg} / \mathrm{dl})$ & $140.25 \pm 17.60$ & $151.11 \pm 17.72$ & 0.083 \\
\hline HDL-C (mg/dl) & $44.88 \pm 8.83$ & $39.89 \pm 6.11$ & 0.062 \\
\hline LDL-C (mg/dl) & $118.00 \pm 25.71$ & $128.22 \pm 32.38$ & 0.320 \\
\hline hs-CRP (mg/dl) & $0.208 \pm 0.069$ & $0.258 \pm 0.091$ & 0.086 \\
\hline \multicolumn{4}{|l|}{ Medication } \\
\hline Anticoagulant & $15(93.8 \%)$ & $18(100 \%)$ & 0.471 \\
\hline ACEI & $9(56.3 \%)$ & $12(66.7 \%)$ & 0.533 \\
\hline ATII & $2(12.5 \%)$ & $3(16.7 \%)$ & 0.725 \\
\hline Beta-blockers & $4(25.0 \%)$ & $6(33.3 \%)$ & 0.595 \\
\hline Nitrate & $10(62.5 \%)$ & $7(38.9 \%)$ & 0.169 \\
\hline СCВ & $2(12.4 \%)$ & $1(5.6 \%)$ & 0.591 \\
\hline Diuretics & 0 & 0 & \\
\hline Statin & $10(62.5 \%)$ & $13(72.2 \%)$ & 0.545 \\
\hline Carvedilol & $6(37.5 \%)$ & $5(27.8 \%)$ & 0.545 \\
\hline
\end{tabular}

Values are mean \pm standard deviation

BMI: Body mass index, TG: Triglyceride, HDL-C: High density lipoprotein cholesterol, LDL-C: Low density lipoprotein cholesterol, hs-CRP: High sensitivity C-reactive protein, ACEI: Angiotensin converting enzyme inhibitor, ATII: Angiotensin II receptor antagonist, CCB: Calcium channel blocker, PW: Power walking group, UW: Usual walking group

$\mathrm{VO}_{2 \max }$ were compared for test variables pre- and post6 -week intervention in both groups. Heart rate (HR), systolic blood pressure (SBP), diastolic blood pressure (DBP), metabolic equivalent (MET), and exercise duration did not show significant differences between the groups. However, $\mathrm{VO}_{2 \max }$ and metabolic equivalent (MET) were significantly higher in PW than in UW after 6 weeks of exercise (Table 2).

\section{Differences in lipid profile and hs-CRP}

Changes in lipid profile and hs-CRP were measured between PW and UW before and after 6 weeks of exercise intervention. All variables of lipid profile and hs-CRP did not show significant changes before and after 6 weeks of exercise between the groups (Table 3 ).

\section{DISCUSSION}

Improved exercise capacity is believed to be more closely related to the peripheral effects than to central effects of the heart in the field of cardiac rehabilitation. ${ }^{16}$ It was noted that peripheral muscles utilize oxygen obtained from aerobic exercises more effectively by increasing the number and size or aerobic related enzymes and mitochondria, as well as increase the level of myoglobin and capillary vessels to the striated muscles. ${ }^{17,18}$ Patients with coronary artery disease can avoid possible physical disability and further prevent recurrence of CAD and mortality.

Myocardial oxygen demands during active daily activities can be diminished through aerobic exercise by increasing maximum oxygen consumption, and decreasing 
Table 2. Comparison of Hemodynamics 6 Weeks after Exercise Program between PW and UW

\begin{tabular}{lccccc}
\hline \multirow{2}{*}{ Variables } & \multicolumn{2}{c}{ Baseline } & & \multicolumn{2}{c}{ After 6 weeks } \\
\cline { 2 - 3 } \cline { 5 - 6 } & $71.19 \pm 12.06$ & $65.11 \pm 6.04$ & PW & UW \\
\hline RHR (bpm) & $146.19 \pm 15.52$ & $135.83 \pm 17.81$ & & $152.44 \pm 9.83^{*}$ & $147.11 \pm 9.27^{*}$ \\
MHR (bpm) & $119.63 \pm 18.34$ & $113.06 \pm 14.16$ & & $114.63 \pm 8.17$ & $121.11 \pm 14.59$ \\
RSDP (mmHg) & $77.13 \pm 7.73$ & $72.17 \pm 8.46$ & & $78.25 \pm 7.07$ & $76.22 \pm 6.67$ \\
RDBP (mmHg) & $176.81 \pm 36.24$ & $175.22 \pm 31.10$ & & $170.75 \pm 22.18$ & $178.89 \pm 24.90$ \\
MSBP (mmHg) & $80.69 \pm 6.90$ & $73.72 \pm 13.35$ & & $76.50 \pm 11.03$ & $74.83 \pm 11.55$ \\
MDBP (mmHg) & $25,870.31 \pm 6,406.93$ & $22,159.94 \pm 6,081.43$ & & $25,936.25 \pm 3,971.94$ & $24,406.06 \pm 5,687.65$ \\
MRPP & $15,254.06 \pm 4,393.14$ & $14,195.06 \pm 3,544.30$ & & $11,869.94 \pm 1,782.00^{*}$ & $12,820.00 \pm 2,364.00^{*}$ \\
SRPP & $28.54 \pm 6.08$ & $27.16 \pm 4.43$ & & $36.03 \pm 5.69^{* \dagger}$ & $29.74 \pm 5.63^{*}$ \\
VO ${ }_{2 \text { Max }}(\mathrm{ml} / \mathrm{kg} / \mathrm{min})$ & $866.63 \pm 107.05$ & $854.67 \pm 106.65$ & & $989.00 \pm 90.25^{*}$ & $944.17 \pm 111.49^{*}$ \\
Duration (sec) & $8.11 \pm 1.84$ & $7.86 \pm 1.27$ & & $10.13 \pm 1.84^{* \dagger}$ & $9.17 \pm 1.08^{*}$ \\
MET & & & & & \\
\hline
\end{tabular}

Values are mean \pm standard deviation

PW: Power walking group, UW: Usual walking group, RHR: Resting heart rate, MHR: Maximal heart rate, RSBP: Resting systolic blood pressure, RDBP: Restig diastolic blood pressure, MSBP: Maximal systolic blood pressure, MDBP: Maximal diastolic blood pressure, MRPP: Maximal rate pressure product, SRPP: Sub-maximal rate pressure product, $\mathrm{VO}_{2 \mathrm{Max}}$ : Maximum oxygen consumption, MET: Metabolic equivalent

${ }^{*} \mathrm{p}<0.05$ by Wilcoxon's signed rank test, ${ }^{\dagger} \mathrm{p}<0.05$ by Wilcoxon's rank-sum test

Table 3. Comparison of hs-CRP and Lipid Profile 6 Weeks after Exercise Program between PW and UW

\begin{tabular}{|c|c|c|c|c|}
\hline \multirow{2}{*}{ Variables } & \multicolumn{2}{|c|}{ Baseline } & \multicolumn{2}{|c|}{ After 6 weeks } \\
\hline & PW & UW & PW & UW \\
\hline Total cholesterol (mg/dl) & $179.94 \pm 45.50$ & $194.56 \pm 43.74$ & $139.69 \pm 27.61^{*}$ & $145.39 \pm 24.62^{*}$ \\
\hline TG (mg/dl) & $140.25 \pm 17.60$ & $151.11 \pm 17.72$ & $113.13 \pm 20.14^{*}$ & $123.33 \pm 18.68^{*}$ \\
\hline HDL-C (mg/dl) & $44.88 \pm 8.83$ & $39.89 \pm 6.11$ & $49.38 \pm 9.32 *$ & $45.28 \pm 7.57^{*}$ \\
\hline LDL-C (mg/dl) & $118.00 \pm 25.71$ & $128.22 \pm 32.38$ & $97.31 \pm 18.80^{*}$ & $97.83 \pm 15.93^{*}$ \\
\hline hs-CRP (mg/dl) & $0.209 \pm 0.067$ & $0.258 \pm 0.087$ & $0.067 \pm 0.0412^{*}$ & $0.087 \pm 0.059 *$ \\
\hline
\end{tabular}

Values are mean \pm standard deviation

PW: Power walking group, UW: Usual walking group, TG: Triglyceride, HDL: High density lipoprotein, LDL: Low density lipoprotein, hs-CRP: High sensitivity C- reactive protein

${ }^{*} \mathrm{p}<0.05$ by Wilcoxon's signed rank test

maximal heart rate and rate pressure product. ${ }^{17}$ The rate of oxygen consumption is determined by the difference between cardiac output and arteriovenous oxygen difference. Cardiac output is decided by stroke volume and heart rate which in turn increase the maximum oxygen consumption. ${ }^{19}$ Although the differences were not observed in systolic blood pressure, diastolic blood pressure, resting heart rate, maximal and sub-maximal rate pressure product before and after 6 weeks of exercise intervention between the groups, significant difference in $\mathrm{VO}_{2 \max }$ was observed between the groups.

The results of the EMG measurements of the upper and lower limbs by Cho et al. ${ }^{20}$ indicated that the muscular activities observed in all upper and lower limb muscles in power walking subjects were greater than that found in those subjects that walked at a slower pace. EMG activities were especially higher in biceps brachii of the upper extremity, and medial gastrocnemius, lateral gastrocnemius, and soleus of the lower extremity. Such results suggest that comparatively higher physical activity ranges and muscular activities during power walking may be related to higher maximal oxygen consumption in comparison to usual walking.

One metabolic equivalent (MET) refers to the amount 
of oxygen consumed during one's resting state $(3.5$ $\mathrm{ml} / \mathrm{kg} / \mathrm{min}$ ). MET is obtained by dividing the value of $\mathrm{VO}_{2 \max }$, acquired during graded exercise test with a gas exchange analyzer, by $3.5 \mathrm{ml} / \mathrm{kg} / \mathrm{min}$. Increased 1 MET is related to decreased risk of death by coronary artery disease in healthy subjects in comparison to unhealthy subjects. Increased 1 MET in those with and without CVD risk factors showed $28-51 \%$ reduction in fatal cardiac death and $17-29 \%$ reduction in non-fatal cardiac death. Therefore, increased 1 MET is a strong risk prognosis factor in cardiac death. ${ }^{21}$ Myers et al. ${ }^{22}$ did a follow-up study with 3,679 patients with coronary artery disease for $6.2 \pm 3.7$ years after measuring their $\mathrm{VO}_{2 \max }$ with graded exercise tests. Exercise capacity of the patients with METs of $\leq 4.9$ METs and $\leq 10.7$ METs had mortality risks of 4.1 and 1.0, respectively. Dorn et al. ${ }^{23}$ reported that the mortality rates of the acute myocardial infarction patients decreased approximately $10 \%$ for every 1 MET increased through the patient progression observations. A significant increase in $\mathrm{VO}_{2 \max }$ alone could have adequate significance, despite the insignificant changes in other variables between PW and UW, based on such previous results. Aerobic exercise plays an important role in cardiovascular disease prevention and offers therapeutic effects by decreasing total cholesterol, triglycerides and increasing high-density lipoproteincholesterol. ${ }^{24}$ Moreover, it has been proven that hs-CRP, a major risk factor marker for mortality in acute myocardial infarction patients, can be decreased through aerobic exercise. Fallon et al. ${ }^{25}$ reported that regularly played soccer decreased hs-CRP concentration. Mattusch et al. ${ }^{26}$ reported that 9 months of endurance running decreased hs-CRP concentration by $31 \%$. Smith et al. ${ }^{27}$ reported that high risk patients $(n=43)$ with ischemic cardiovascular disease had $35 \%$ reduction in TNF- $\alpha$ and hs-CRP after 6 months of exercise. In this study, hs-CRP and lipid profile significantly decreased post-exercise in both groups without significant changes in between groups.

Myocardial oxygen consumption during exercise indicates the rate pressure product (RPP) during equal workloads. It plays a vital role in decreasing the incidence of angina due to its close relationship to angina threshold. Additional previously studies have reported that an increased myocardial ischemic threshold by physical activity for anti-ischemic effects further increased the ability to perform at greater work intensities. ${ }^{28}$ Ahn et al. ${ }^{29}$ reported that the rate pressure product was significantly lowered in myocardial ischemia patients that exercised in comparison to myocardial ischemia patients that did not exercise, with a significant decrease in maximal pressure rate product at equal workloads. Such significant improvement can be credited to regular aerobic exercise by improving exercise tolerance and exercise duration, as well as increasing heart rates and systolic blood pressure. There are some limitations to this study, which should be considered in future studies. The limitations include an inadequate number of patients and 6 weeks of shortterm exercise intervention for adequate observation of the significant changes in variables. Further studies should be conducted with an adequate number of patients with long-term observation of their progress.

\section{CONCLUSION}

The significantly increased maximum oxygen consumption $\left(\mathrm{VO}_{2 \max }\right)$ of the power walking group with acute coronary syndrome in comparison to the usual walking group with coronary syndrome suggests the possibility that power walking should be part of the recommendation for a more aggressive mode of cardiac rehabilitation exercise.

\section{REFERENCES}

1. Thompson PD, Buchner D, Pina IL, Balady GJ, Williams MA, Marcus BH, Berra K, Blair SN, Costa F, Franklin B, et al. Exercise and physical activity in the prevention and treatment of atherosclerotic cardiovascular disease: a statement from the Council on Clinical Cardiology (Subcommittee on Exercise, Rehabilitation, and Prevention) and the Council on Nutrition, Physical Activity, and Metabolism (Subcommittee on Physical Activity). Circulation 2003; 107: 3109-3116

2. Kelley GA, Kelley KS, Tran ZV. Walking, lipids, and lipoproteins: a meta-analysis of randomized controlled trials. Prev Med 2004; 38: 651-661

3. Kelley GA, Kelley KS, Tran ZV. Walking and resting blood pressure in adults: a meta-analysis. Prev Med 2001; 33: 120-127

4. Franklin BA. Walking: the undervalued prescription. Prev Cardiol 2006; 9: 56-59 
5. Quell KJ, Porcari JP, Franklin BA, Foster C, Andreuzzi RA, Anthony RM. Is brisk walking an adequate aerobic training stimulus for cardiac patients? Chest 2002; 122: 1852-1856

6. Tully MA, Cupples ME, Chan WS, McGlade K, Young IS. Brisk walking, fitness and cardiovascular risk: a randomized controlled trial in primary care. Prev Med 2005; 41: 622-628

7. Aamot IL, Moholdt T, Amundsen BH, Solberg HS, Mørkved S, Støylen A. Onset of exercise training 14 days after uncomplicated myocardial infarction: a randomized controlled trial. Eur J Cardiovasc Prev Rehabil 2010; 17: 387-392

8. Morris JN, Hardman AE. Walking to health. Sports Med 1999; 23: 306-332

9. Hardman AE, Jones PR, Norgan NG, Hudson A. Brisk walking improves endurance fitness without changing body fatness in previously sedentary women. Eur J Appl Physiol Occup Physiol 1992; 65: 354-359

10. Greiwe JS. Hickner RC, Shah SD, Cryer PE, Holloszy JO. Norepinephrine response to exercise at the same relative intensity before and after endurance exercise training. J Appl Physiol 1999; 86: 531-535

11. Martin PE, Rothstein DE, Larish DD. Effects of age and physical activity status on the speed-aerobic demand relationship of walking. J Appl Physiol 1992; 73: 200206

12. Park DS, Nam HS, Kim DH, Her JG, Woo JH. The comparison of exercise intensity between power walking and running. J Korean Sports Med 2008; 26: 175-179

13. Butts NK, Knox KM, Foley TS. Energy costs of walking on a dual-action treadmill in men and women. Med Sci Sports Exerc 1995; 27: 121-125

14. Gibbons RJ, Balady GJ, Bricker JT, Chaitman BR, Fletcher GF, Froelicher VF, Mark DB, McCallister BD, Mooss AN, O'Reilly MG, et al. ACC/AHA 2002 guideline update for exercise testing: summary article. A report of the American College of Cardiology/ American Heart Association Task Force on Practice Guidelines (Committee to Update the 1997 Exercise Testing Guidelines). J Am Coll Cardiol 2002; 40: 15311540

15. Karvonen MJ, Kentala E, Mustala O. The effects of training on heart rate; a longitudinal study. Ann Med Exp Biol Fenn 1957; 35: 307-315

16. Scheur J, Tipton CM. Cardiovascular adaptations to physical training. Annu Rev Physiol 1997; 39: 221-251

17. Holloszy JO. Biochemical adaptations in muscle. Effects of exercise on mitochondrial oxygen uptake and respiratory enzyme activity in skeletal muscle. J Bio Chem 1967; 242: 2278-2282

18. Kraus WE, Houmard JA, Duscha BD, Knetzger KJ, Wharton MB, McCartney JS, Bales CW, Henes S, Samsa GP, Otvos JD, et al. Effects of the amount and intensity of exercise on plasma lipoproteins. N Eng J Med 2002; 347: 1483-1492

19. Fletcher GF, Balady GJ, Amsterdam EA, Chaitman B, Eckel R, Fleg J, Froelicher VF, Leon AS, Pina IL, Rodney R, et al. Exercise standards for testing and training: a statement for healthcare professionals from the American Heart Association. Circulation 2001; 104: 1694-1740

20. Cho KK, Kim YS, Kim EJ. The Comparative analysis of kinematic and EMG on power walking and normal gait. Korean J Sport Biomechanics 2006; 16: 85-95

21.Laukkanen JA, Kurl S, Salonen R, Rauramaa R, Salonen JT. The predictive value of cardiorespiratory fitness for cardiovascular events in men with various risk profiles: a prospective population-based cohort study. Eur Heart J 2004; 25: 1428-1437

22. Myers J, Prakash M, Froelicher V, Do D, Partington S, Atwood JE. Exercise capacity and mortality among men referred for exercise testing. $N$ Engl J Med 2002; 346: 793-801

23. Dorn J, Naughton J, Imamura D, Trevisan M. Results of a multicenter randomized clinical trial of exercise and long-term survival in myocardial infarction paients: the National Exercise and Heart Disease Project (NEHDP). Circulation 1999; 100: 1764-1769

24. Sun Y. Study of exercise and serum lipids in puberty. Zhonghua Liu Xing Bing Xue Za Zhi 1991; 12: 193-196

25. Fallon KE, Fallon SK, Boston T. The acute phase response and exercise: court and field sports. Br J Sports Med 2001; 35: 170-173

26. Mattusch F, Dufaux B, Heine O, Mertens I, Rost R. Reduction of the plasma concentration of C-reactive protein following nine months of endurance training. Int J Sports Med 2000; 21: 21-24

27. Smith JK, Dykes R, Douglas JE, Krishnaswamy G, Berk S. Long-term exercise and atherogenic activity of blood mononuclear cells in persons at risk of developing ischemic heart disease. JAMA 1999; 281: 
Chul Kim, et al.

1722-1727

28. Shephard RJ, Balady GJ. Exercise as cardiovascular therapy. Circulation 1999; 99: 963-972

29. Ahn JK, Kim C, Bang IK, Kim YJ. Effectiveness of cardiac rehabilitation on exercise capacity and ventricular function in ischemic heart disease patients. J Korean Sports Med 2006; 24: 229-236 